an experiment in which the external resistance was $\mathrm{I}$ ohm, and the internal $0.58 \mathrm{ohm}$, the E.M.F. sank in forty-five minutes from 2.25 to $I^{\circ} 92$, but after being disconnected for thirty minutes, it was found to have risen to $1 \cdot 96$, and after eighteen hours' repose it had actually risen to I 98 volts. These observations were made many times in succession during the course of the experiment, which lasted six days.

With twenty times the external resistance, the diminution of electromotive force was much slower; but after discharging three days, the fall was more pronounced, and the rise on repose very apparent.

With $100 \mathrm{ohms}$ resistance, the electromotive force varied very little for three days.

It is more difficult to obtain satisfactory chemical evidence of a quantitative character. It is clear that as chemical examination means the destruction of the substances, the same plate cannot be analysed in two consecutive stages. Nor can two plates be easily compared with one another, although they have been formed under the same circumstances. Even the same positive plate, during or after discharge, presents to the eye very different appearances in different parts. To a certain extent we obviated this difficulty by cutting the plate in two, longitudinally, analysing the one half at once, and allowing the other to repose for a given time before examining it for peroxide of lead.

As to the estimation of peroxide in the presence of metallic lead, we finally adopted as the best method that of reducing it by means of oxalic acid, although we were not certain that the whole amount is obtained in this way, even though the solution be kept hot for a considerable time.

By this method many chemical examinations were made of the positive plate. The results are as follows :First of all, when the external resistance did not exceed $20 \mathrm{ohms}$, the peroxide of lead was generally visible in patches, and its presence was demonstrated and approximately measured by various chemical tests. On repose, the quantity of this peroxide visibly diminished, and in the majority of instances the chemical analyses also showed a smaller amount. In all cases sulphate of lead makes its appearance early in the action, and gradually increases in quantity, becoming finally the only product of the discharge.

The deposit on the negative plate shows the presence of nothing but sulphate of lead in addition to the unchanged peroxide. At the conclusion of the action, we have always found more or less of this substance unaltered. Thus, as one instance, after a discharge lasting five days, and approximately complete, we found that only 68 per cent. of the deposit was lead sulphate.

We conclude therefore that the chemical action of the discharge is essentially what is expressed by the following theoretical formula :-

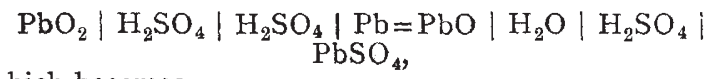
which becomes

$$
\mathrm{PbSO}_{4}\left|\mathrm{H}_{2} \mathrm{O}\right| \mathrm{H}_{2} \mathrm{O} \mid \mathrm{PbSO}_{4} \text {. }
$$

This reaction is, however, sometimes complicated by the formation of a small amount of peroxide of lead on the positive plate. We believe this to be due to the oxidation of sulphate, an action which was explained in our last paper.

Another conclusion has reference to the resuscitation of power observed on repose. This is not due to any purely physical action but is a necessary consequence of the formation of $\mathrm{PbO}_{2}$ on the pasitive plate. As sooner or later the result of the action becomes solely $\mathrm{PbSO}_{4}$, this temporary formation of peroxide does not seriously affect the quantity of electrical force that may be regained from the accumulator, but it does affect the evenness of its flow. The flow is more regular if the discharge be made slowly, but in that case the loss on the negative plate from local action will probably be 'greater.

As to practical conclusions, we may note-I. Although, as stated in our paper of March 9 , the most economical arrangement for the initial charging of the cell is to "make the red lead to be hydrogenated much smaller in amount than that to be oxidated," yet, as foreshadowed in the same paper, this arrangement is not desirable for the discharge of the cell. Nor is it for its subsequent charging, since, as will have been seen, the substances to be acted upon are now very different. On the negative plate there will be the sulphate of lead produced by the discharge, plus sulphate of lead produced by local action, together with more or less unaltered peroxide. On the positive plate there will be the sulphate of lead produced by the discharge, together with excess of lead, if any. Unless, therefore, the peroxide of lead unacted upon is allowed to be very considerable, the quantity of lead compound on the two sides ought to approach equality. 2. Care should be taken that sulphuric acid is in sufficient excess to allow of there still remaining some of it in solution after all the available lead has been converted into sulphate. If it is removed and only water is present, an oxide or hydrate will be produced with probably some serious consequences to the cell.

July 3

J. H. Gladstone ALFRED TRIBE

ON THE DEVELOPMENT OF THE CROCODILIAN SKULL

THE most striking thing in the development of the Crocodile is the structure of its visceral arches, and especially those that form the jaws and the hyoid or lingual arch.

(a) Endoskeletal Parts of the Upper Jaw.-Inside the massive outer bones of the upper face, or maxillaries and

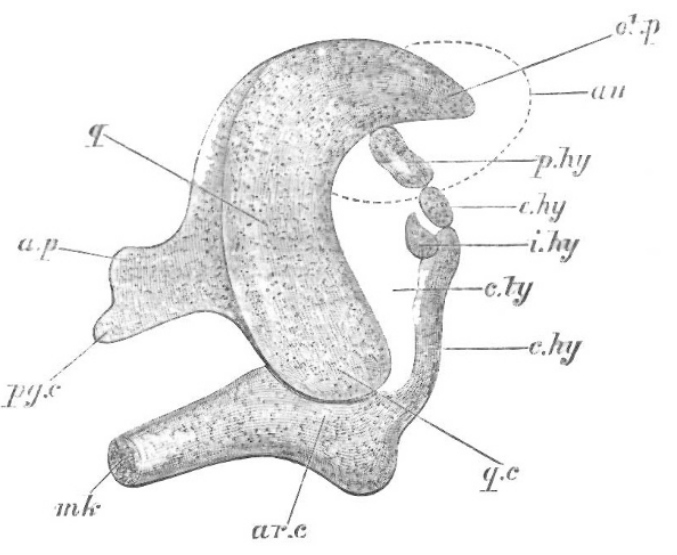

FIa, l.

$\times 13$

FIG. I.-Upper part of mandibular and hyoid arches, outer view of second

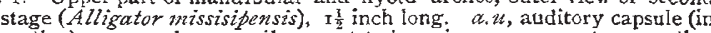
outline); q. quadrate cartilage; ot.p, its otic process; $a . p$, ascending process; pg.c, pterygoid cartilage; q.c, condyle of quadrate; $m k$, Meckel's cartilage; ar.c, condyle of articular region of mandible; $p . h y$, pharyngo-hyal; e.hy, epi-hyal; $i . h y$, inter-hyal; c.hy, cerato-hyal.

jugals, there are the more delicate palatines, transpalatines, and pterygoids. These are formed in a membranous tract of the palate, and but little cartilage, such as is seen in fishes, makes its appearance.

The pterygoids assist the palatines and maxillaries in forming the "hard palate" or secondary floor to the nasal passages, just as in the Ant-bear, Tamandua, and some Cetacea amongst the Mammalia. This hard palate is not seen in Snakes, Lizards, and the smaller Tortoises, but is developed in some degree in the large Turtles. It is but little developed in Birds ; for in them only a few 
such as the Hornbill and Podargus have the palatines meeting at the middle below.

The quadrate is very huge in the Crocodilia, and is fixed as in the Turtle and its congeners, and as in them it forms the greater part of the tympanic cavity ; in Snakes, Lizards, and Birds the quadrate, or pier of the lower jaw, is movable.

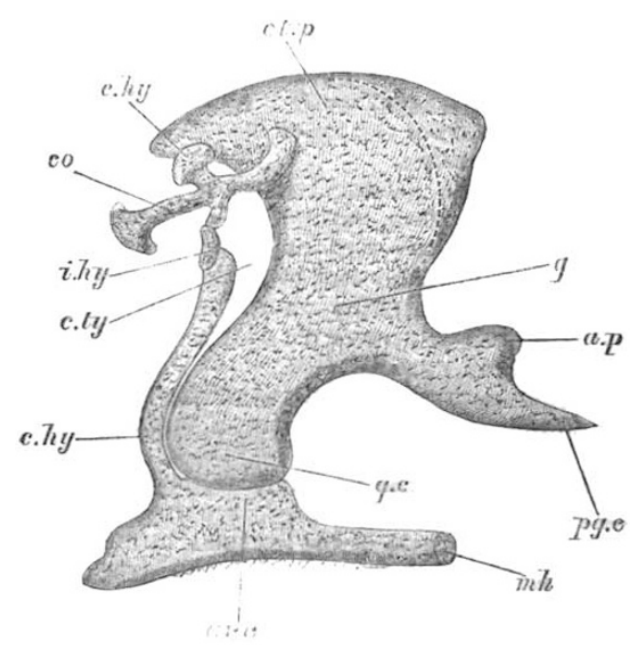

Fic. 2.

$\times 10$.

FIG. 2.-Upper part of mandibular and hyoid arches of third stage (Crocodilus palustris) outer view, $x_{6}$ inch long. Letters as in Fig. 2, except co, columella.

In Salamanders the quadrate cartilage grows up to the top of the skull, in front of the ear-capsule; this part is called the "ascending process; the other fork runs inwards under the fifth nerve, and is either articulated to or fuses with the basis cranii.

In all lizards except the Chameleons such an ascending process is found, but it is segmented off from the quadrate and becomes ossified as the "columella," which supports

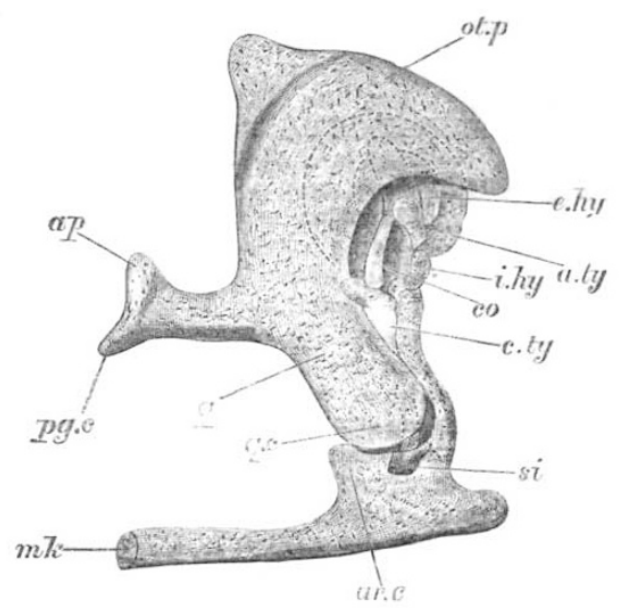

Fic. 3.

$\times 6$

Frg. 3.-Same part of same species (fourth stage), $3 \frac{1}{2}$ inches long, as Fig. 2 (inner view); a.ty, cartilaginous annulus tympanicus.

the roof (this is not the auditory columella, or stapes); I call the former the "epipterygoid." In the Crocodile there appears, very early, a forked process to the quadrate; here the upper fork is the rudiment of the ascending process or "columella," and the horizantal fork is a rudiment of the pterygoid cartilage, which is so large in Sharks and Skates, and forms their upper jaw.
The lower jaw of the Crocodilia corresponds with that of the other Sauropsida-the other Reptiles and Birds, being composed of six splint bones, and an ossification of the articular end of the cartilage, "articulare internum," which unites with the nearest splint, "articulare externum," to form one bone, this, however, is pneumatic, the cartilage itself being hollowed out and com-

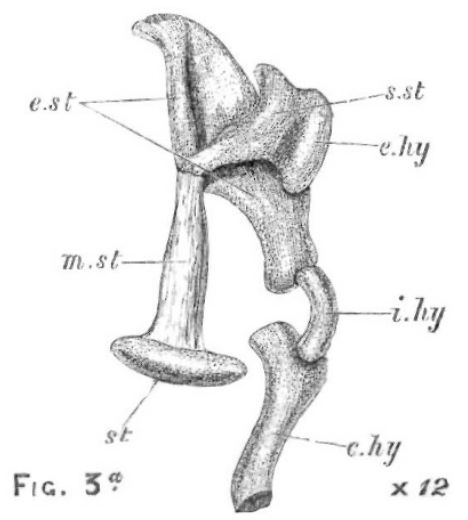

F1G. 3a.-Part of same object as Fig. 3 (inner view). Letters same as last; with addition of st, stapedial plate; $m$,st, medio-stapedial; e.st, extrastapedial; s.st, supra-stapedial.

municating by a tube with the cavity of the ear-drum. That tube is called the "siphonium," and Prof. Huxley (see Proc. Zool. Soc., May 27, 1869, p. 391) thought that Prof. Peters had mistaken this tube for a rod of cartilage, which the latter described ("Monatsber. König. Akad. der Wissensehaft. zu Berlin," November, 1868, p. 592) as running directly from the auditory columella into Meckel's cartilage. Such a continuity of the auditory columella

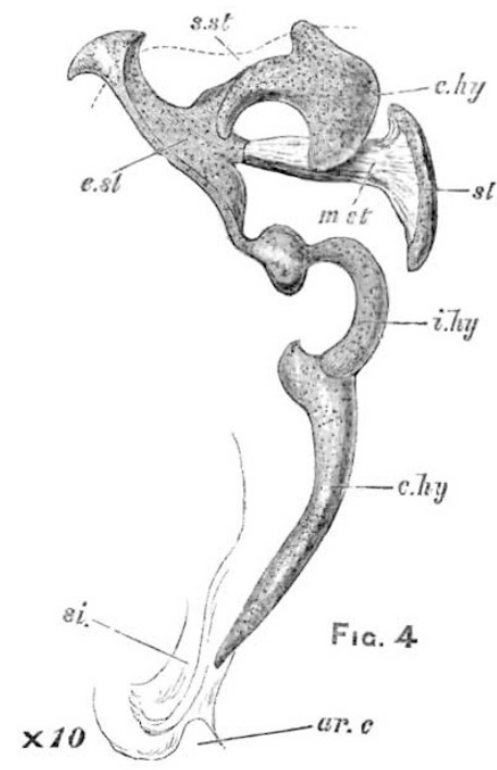

FIG. 4.-Same species as last (fifth stage, $4 \frac{1}{2}$ inches long), outer view. Lettering the same, with addition of $s i$, siphonium.

(stapes and incus in one) with the hyoid arch and the endoskeletal lower jaw does, however, exist from an early period, up to the middle of incubation. Prof. Peters' observations were made upon small embryos, Prof. Huxley's upon ripe young; the former observed rightly, but his reasoning upon the facts seems to me to be quite at fault; Prof. Huxley had not the proper materials to work upon, but his reasoning was perfect, and the truth of his 
deductions, in spite of his mistake about the temporary continuity of the mandibular and hyoid arches, appears to me to be absolutely incontrovertible.

As far as I have seen, there is no other type in which the hyoid "cornu" is chondrified continuously with Meckel's cartilage, or the endoskeletal lower jaw.

This may be an acquired peculiarity, but I rather incline to the view that it is an old hereditary characteristic,

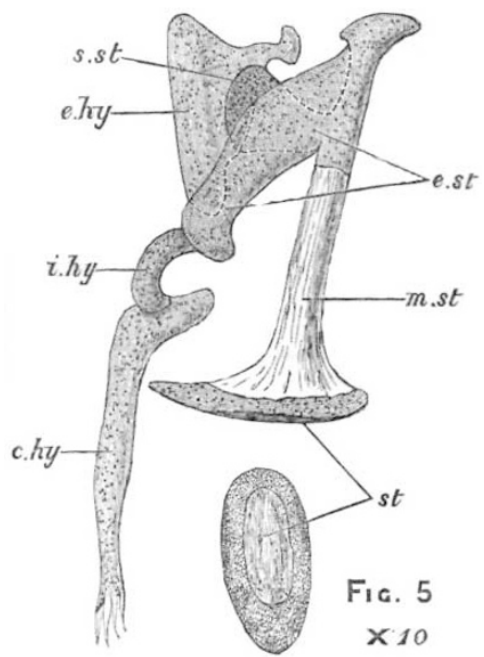

FIG. 5.-Same species as last (same stage, more advanced, 5 inches long), outer view. Lettering the same; the internal face of the stapes, $s t$, is shown.

derived from a very remote ancestry, in which the visceral arches formed a basketwork of cartilage, and not a series of properly segmented arches, such as we are familiar with in most fishes. In some fishes, the "marsipobranchii"-Hag and Lamprey-we still see this lower, non-differentiated state of things.

There is a small distal part to the lingual or hyoid arch, but the lower part of the "cornu" (cerato-hyal) is

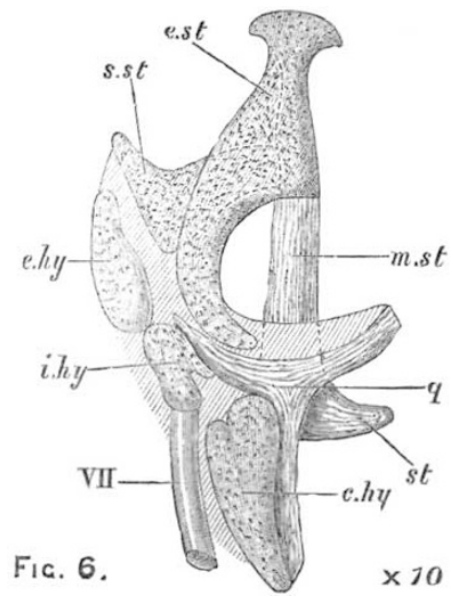

FIG. 6.-Same species as last (seventh stage, ripe embryo, ro inches long) outer view. Lettering the same, with addition of $q$, quadrate bone; vir., facial nerve.

aborted by the continuity of its upper half with the lower jaw.

The rest of the arch resembles the branchial arch of a fish, and is like the proper hyoid arch of a Chimæra ; the segments correspond very closely, but there is one piece too many, but this intercalary piece-the "inter-hyal"is found in ganoid and osseous fishes-uniting their hyomandibular with their epihyal.
This fish-like hyoid soon becomes a continuous bar, as in the New Zealand Lizard (Hatteria), where the auditory columella and the hyoid arch are one continuous structure.

That condition, however, in the Crocodile, is only continued through the middle part of the term of incubation; towards the latter part of the time the parts that were fused all come to pieces again, and the ripe young has a free columella, with small, distinct nuclei of cartilage attached to the hinder margin of the ear-drum, these are remnants of the epi-, inter-, and cerato-hyals-the latter become free from the lower jaw during the middle of the incubating period.

The complex triple Eustachian tubes are formed after the middle of incubation, but before that time the basis cranii had become hollowed out, and so also had the quadrate and the articular end of the mandible.

By the time of hatching there are in the complex tympanic labyrinth or diverticula of the Ist visceral cleft, the following parts, namely :-

a. The drum-cavity hollowed out of the quadratum.

$b$. The middle, single, and the lateral, forked Eustachian tubes.

c. The extension of the tympanic cavity into the whole posterior sphenoid, base and wings, into the periotic bones, and into the whole circle of the occipital arch or ring.

$d$. Through the "siphonium," into the articular region of the lower jaw.

The investing bones are solid; only the ossifications of the primary chondrocranium are pneumatic; this hollowing out begins to take place before ossification sets in.

The pneumaticity of the Crocodile's endocranium is similar to what obtains in birds, the whole tympanic labyrinth in the two types is singularly like, and singularly unlike.

Note.-For descriptions of these parts in the bird-class I must refer the reader to my papers in the Royal, Linnean, and Zoological Societies. A full account of the development of the skull of the Crocodilia will soon appear in the Transactions of the latter society.

W. K. PARKER

\section{PROF. HAECKEL IN CEYLON AND INDIA \\ I.}

PROF. ERNST HAECKEL of Jena, as most of the readers of NATURE are doubtless aware, has lately returned to his University after a six months' journey in India and Ceylon, undertaken in the interests of science with the object of providing additional data in support of the theory of evolution, of which he is the most able and best-known exponent in Germany. The veneration which he constantly expresses for Mr. Darwin, of whom he may be said to have been the first and perhaps the chief disciple on the Continent, would of itself suffice to give his opinions and observations weight in this country. No one, however, who has read the series of letters now being contributed by Prof. Haeckel to the Deutsche Rundschau, can fail to find them on their own merits both delightful and instructive. They are written in a popular form, but contain traces of profound scientific knowledge combined with great quickness and freshness of observation, and an almost boyish exuberance of delight in the presence of nature's wonders. Of the three letters or articles already published, the first contains an account of the voyage to India, the second, entitled "A Week in Bombay," describes with vivid enthusiasm the caves of Elephanta and the other marvels of that most interesting of tropical cities, and the third, contained in the June number of the Rundschau, of which we propose to give a short reproduction for the benefit of our English readers, brings the Professor to the "promised land" of his scientific yearnings-that island of Ceylon which exhibits in all its varied 